\title{
Leadership Management among Construction Professionals in the Context of Nepal
}

\author{
Khet Raj Dahal ${ }^{1 *}$ and Manoj KC ${ }^{2}$
}

${ }^{1}$ Centre for Post-Graduate Studies, Nepal Engineering College, Kathmandu, Nepal

${ }^{2}$ Civil Engineer, Kathmandu Valley Development Authority, Nepal

\begin{abstract}
This study, "Leadership in Construction Management among Construction Professionals in the Context of Nepal", was conducted during the period from March to November in 2015. For this purpose, field survey was conducted through semi-structured questionnaire. Sample survey among professional practitioners was conducted in Kathmandu valley. The findings of the study reveal that construction professionals realize the effective leadership in different levels and dimensions in Nepalese construction industries. In addition, the study has shown the relevancy of authentic leadership in order to overcome challenges like corruption and unsophisticated organizational context. At the same time, the study highlights the various requirements to update the priority of leadership traits towards skills, such as, communication, motivation rather than limiting only to hard core skills. Similarly, leadership behavior was found out to be oriented towards higher level people of management. Furthermore, the study has also demonstrated that construction professionals are not adequately strong in key dimensions of authentic leadership. Hence, leadership development should be given equal emphasis on technical and managerial aspects in construction industries along with the professionals in the circumstance of Nepal.
\end{abstract}

Keywords: Construction industries; Clients; Contractors; Leadership management; Professionals

\section{Introduction}

Construction is a human attempt to build facilities for the people's welfare. The term 'Construction Leadership' is defined as the leadership relevant to the management of construction process, projects and products. Leadership is important in all fields of human endeavor. Features of the construction process and construction projects render leadership even more essential [1,2]. Leadership occupies a broader meaning than the than the leaders [3]. Leadership needs in every sector of human society along with construction industries.

The construction industry has a greater need for leadership than, arguably, any other field of endeavor. Many reasons support this contention and are evident in the nature of the construction projects, industry and constructed products [4]. Developing countries have an even greater need for leadership in construction for abundant reasons such as poor project performance deficiencies, problematic operating environments, direct relation of constructed products with long term socio economic development and finally the stakeholders are unaware of the many aspects of construction [1,2]. Nepalese Construction Industry has its own challenges of its own in many levels and dimensions of construction and development such as poor design and quality of projects [5], inappropriate construction policy, lack of professional development justifying the need for research on construction leadership in Nepalese Construction industry.

Despite this recognition that leadership is important at all levels of the construction industry, emphasis is placed on the technical aspects, as well as management and leadership receives inadequate attention $[6,7]$.

"Leadership is a process of motivating people to work together collaboratively to accomplish great things" [8]. "Leadership is something larger than the leaders-that leadership encompasses all there is that defines who a leader may be" [3].

Finding one specific definition of leadership is very complex task as studies on this topic are varied and there is no single generally accepted definition [9].
Despite these differences in definitions, there is consensus in common leadership notions such as influence, motivation, common goals.

Leadership and management are two terms that are often confused. Not all leaders are managers and not all managers are leaders [10]. While highlighting the importance of both [11], argues that "managers promote stability while leaders press for change and any industry that embraces both sides of the contradiction can survive in turbulent times." This research shall use the terminology construction leadership as the leadership relevant to management of construction process, projects and products.

Early theories of leadership developed before 1980s focused on supervisory nature of leadership. They were namely i) trait theories ii) behavioral theories, iii) Contingency theories [12].

There are three well known studies on leadership behavior. They are i) Ohio state studies, ii) Michigan studies, iii) Blake and Mouton's Leadership Grid studies. First two studies were done around 1940s and 1950s which consider two dimensions by which leadership behavior can be characterized : i) Orientation towards people and ii) Orientation towards task. Using these two dimensions Blake and Mouton developed a graphical portrayal called leadership grid showing various ranges of leadership styles.

This managerial grid is widely used by practitioners and management trainers because of its simplicity and intuitive appeal,

*Corresponding author: Khet Raj Dahal, Visiting Professor, Centre fo Post-Graduate Studies, Nepal Engineering College, Kathmandu, Nepal, Tel: +(977)015090744; E-mail: dahal.khetraj@gmail.com

Recieved June 10, 2016; Accepted June 21, 2016; Published June 28, 2016

Citation: Dahal KR, Manoj KC (2016) Leadership Management among Construction Professionals in the Context of Nepal. J Entrepren Organiz Manag 5 : 187. doi:10.4172/2169-026X.1000187

Copyright: $\odot 2016$ Dahal KR, et al. This is an open-access article distributed unde the terms of the Creative Commons Attribution License, which permits unrestricted use, distribution, and reproduction in any medium, provided the original author and source are credited. 
although there is little empirical evidence to suggest which of the style is best in all situations [10].

In construction Industry there is no one best style of leadership and construction managers have to wear different hats in dealing with the stakeholders both within the industry and outside the industry. The main objective of this study was to explore the understanding of the concept of "construction leadership" among practitioners in the context of Nepal.

\section{Materials and Methods}

The Study Area was entities such as Government organizations, contractors /developers organizations, Engineering and Architectural Firms, Professional bodies, Educational Institutions involved in construction Industry of Nepal. Kathmandu valley and its vicinity was selected as the area of study since most of the interest of this study were stationed here in the valley and thought to be sufficient for the scope of this Study.

The study followed perception based sample survey method. The answers to seven specific research questions were found out by careful observation of the phenomenon of construction leadership among selected samples through the responses to Four (4) sets of carefully designed leadership questionnaire in addition to separate set for obtaining demographic information of the construction professionals. The survey included research variables such as (i) need for leadership (ii) dimensions of problems in construction,(iii) causes of poor construction, iv) appropriate solutions to overcome poor performance (v) leadership skills/traits (vi) leadership behavior orientation/styles, and (vii) key dimensions of authentic leadership development. Also relationship of these variables was established with various situational factors such as level of industry, age and experience, job type and position, organization type etc. obtained through the demographic information of respondents. This Study simply explored the various construction leadership trends prevalent among Nepalese Construction Industry practitioners and assumed sample survey method would be appropriate to find the answers to these research questions.

Mixed method of research approach was taken to meet the objectives of this research. Basically Descriptive statistics such as Measures of centre and location like Mean, Frequency analysis, Percentages, Relative Average Index, Standard Deviation were used to measure the research variables while measures such as ANOVAs Table and Paired T-test were used to demonstrate the relationship between some of these variables and situational factors like level of industry, organization type, Age and experience etc.

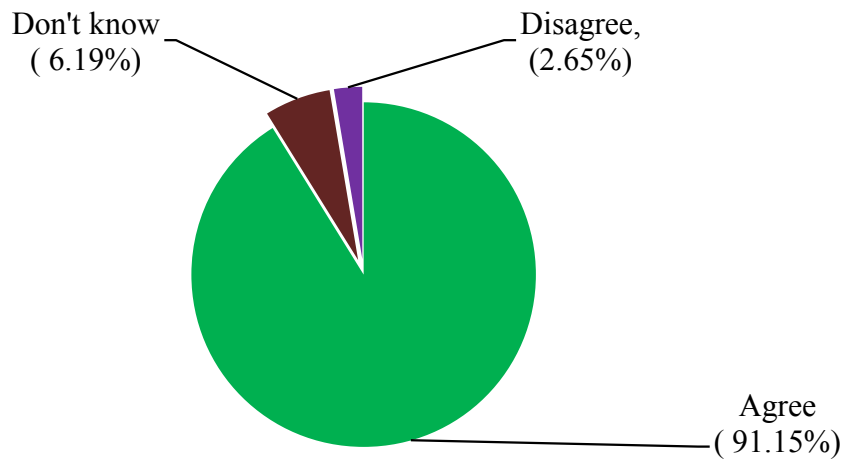

Figure 1: People's perception on the importance of leadership.
The study population were the practitioners involved in three typical participants of Nepalese construction industry i.e. (i) client, government departments and organizations (ii) contractor, which this study included general contractors, developers and subcontractors, which are working in various construction projects, and (iii) consultant, which included engineering and architectural consultant firms, experts working as freelancers giving consultancy services to the client.

Again, the population was selected in order to assimilate professionals involved in all three levels of the industry which this study categorized into (i) policy/institution level professionals involved in policy making and promoting professionalism taking executive positions in various professional societies, Joint secretaries of ministries, retired high government officials and faculties of engineering institutions (ii) organization level professionals involved in leading their organizations with innovation and competency such as managing directors and top executives of private firms, senior divisional engineers and architects of government organizations, fresh engineer/entrepreneurs and lastly (iii) project level professionals involved directly in construction projects in various positions ranging from project manager, site manager, project engineer, procurement manager

This study preferred convenient quota sampling technique as the best fit technique for selecting sample population. Quota was given to each three typical participants; client, consultant and contractor and care were also taken in order to involve all levels of professionals. Samples were interviewed as per the convenience and availability of the respondent's (i.e. willingness to participate in the survey).

\section{Results and Discussion}

\section{Need of leadership in construction industries}

The respondents were asked about the importance of leadership in Nepalese construction industries. The answer was different. There were three options of this question: agree, disagree and don't know. The result is presented in Figure 1. Ninety one percent of the total respondents (91\%) agreed to the statement i.e. effective leadership is one of the primary answers to the problems in Nepalese construction Industry. This statistic indicated that maximum number of respondents realized the need of leadership in construction in Nepal. These responses from all three levels of the industry as categorized by this study were analyzed to find out if need for leadership is felt at all levels of Nepalese construction industry (Figure 1). Similarly, the realization of leadership in different three levels: organization level, policy level and project level. The respondents answered differently. The result is presented in Figure 2. More than $85 \%$ answered it was necessary in organization level, more

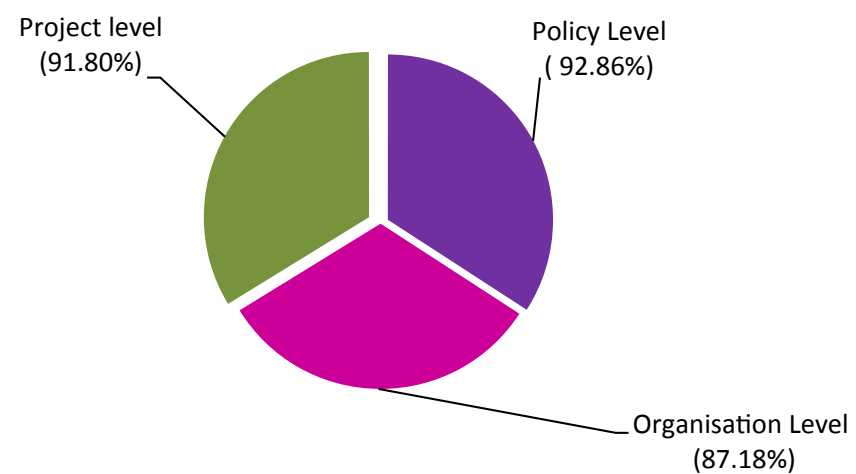

Figure 2: Realization of need for leadership at various levels. 
than $92 \%$ answered that it was necessary in policy level, and more than $91 \%$ felt that it was necessary in organization level. The result is presented in Figure 2.

\section{Reasons justifying the need for leadership}

In this regards, respondents were asked to choose among the best reason/s justifying the need for leadership in Nepalese construction industry. There were five options to choose from. Some respondents selected more than one options as their answers to this question. The distributions of responses among the five options are illustrated in Figure 3.

The results indicated that Nepalese construction industries have many unique problems, which suggest that Nepal has even greater need for leadership in many levels and dimensions as in the case of many developing countries $[1,2,13]$. More than $55 \%$ (55.75\%) of respondents pointed out all the four reasons listed in the questionnaire as equally justifiable for the need of leadership in Nepalese construction industry. Similarly, $24.78 \%$ of respondents pointed out the project performance deficiencies were the main issue to be addressed through effective leadership. Remaining $7.96 \%$ of respondents saw the problems in Project management itself, which need to be addressed while equal percentages of respondent pointed out the need to educate many aspects of construction to end users, clients themselves through effective leadership. While meager (5.31\%) of the respondents considered long term implications of the completed projects or products are critical to socio-economic development of Nepal. Hence, poor performances have adverse implications to the nation as a whole.

\section{Major causes of poor construction performance}

In this regard, maximum number of respondents accepted that construction performance is poor in many levels and dimensions of industry and considered effective leadership as one of the primary answers to these problems. The specific major causes of poor construction performance were investigated through the answers given by the respondents. The results from the respondents are represented in Figure 4.

Many respondents selected more than one reason for poor construction performance. Among them corruption and inappropriate construction policy stand out at the top with $30.97 \%$ for each. Next $25.66 \%$ of the respondents felt ethical leadership is decreasing among the professionals. Lack of political will from the leaders occupying formal leadership position stands as next at $22.12 \%$, while poor operating environment comes at $18.58 \%$ and lastly weak bureaucratic structure comes at $15.04 \%$ (Figure 4). Negative trends like corruption, decrease in ethical leadership, and lack of political will on the one side reflect negative psychology among practitioners, while inappropriate construction policy, weak bureaucratic structure and poor operating environment reflect under developed organizational context in Nepalese construction industry. These results indicate the relevancy of authentic leadership in Nepalese construction industry because authentic leadership is a process that draws from both the positive psychological capacities and a highly developed organizational context, which results in both greater self-awareness and self-regulated positive behaviors on the part of leaders fostering positive self-development [14].

\section{Solutions to overcome poor construction performance}

The last question of this part of questionnaire was about recommended solutions to overcome poor construction performance. There were 5 (five) options to choose from. The respondents answered differently and the result is presented in Figure 5.

The respondents were also asked to recommend solutions other than that specifically mentioned in the questionnaire under "others" option. The answers ranged from (i) effective monitoring and evaluation (ii) proper incentives and effective reward system (iii) awareness of quality consciousness (iv) technically as well as managerially competent project manager (v) accountable to one's duty by each citizen (vi) high level of ethics (vii) good governance in each area (viii) trained construction workers, and (ix) strong leadership in all phases of project.

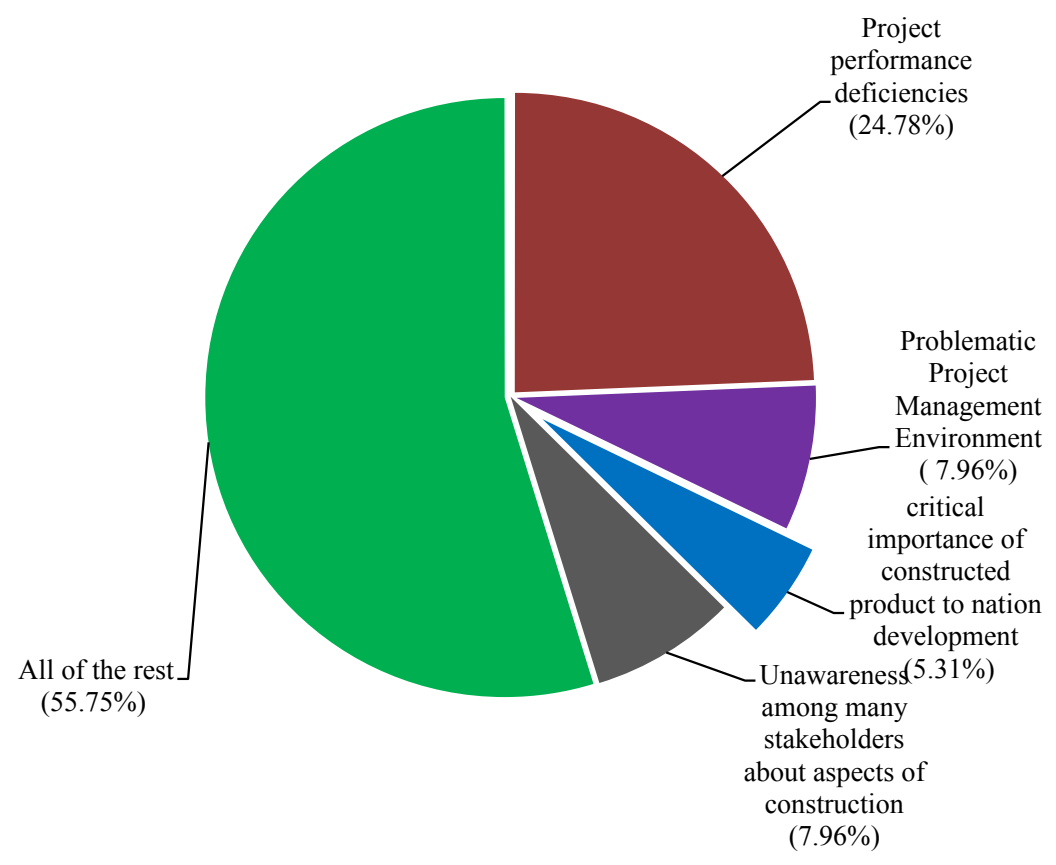

Figure 3: Reasons justifying the need for leadership. 


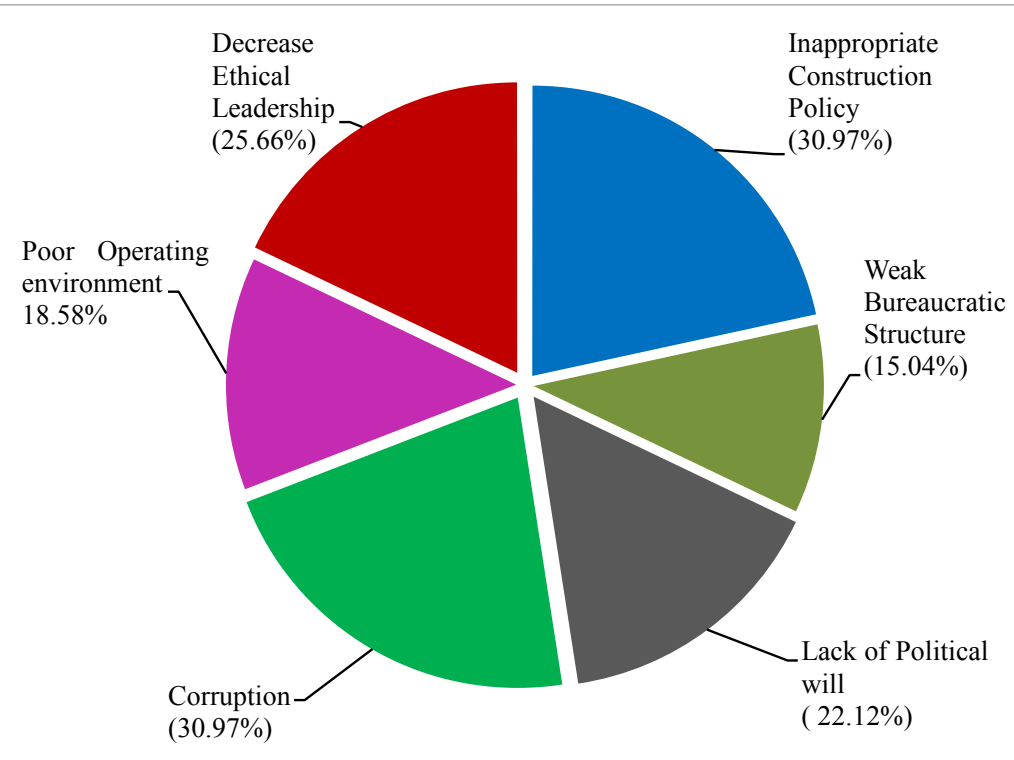

Figure 4: Major causes of poor construction performance.

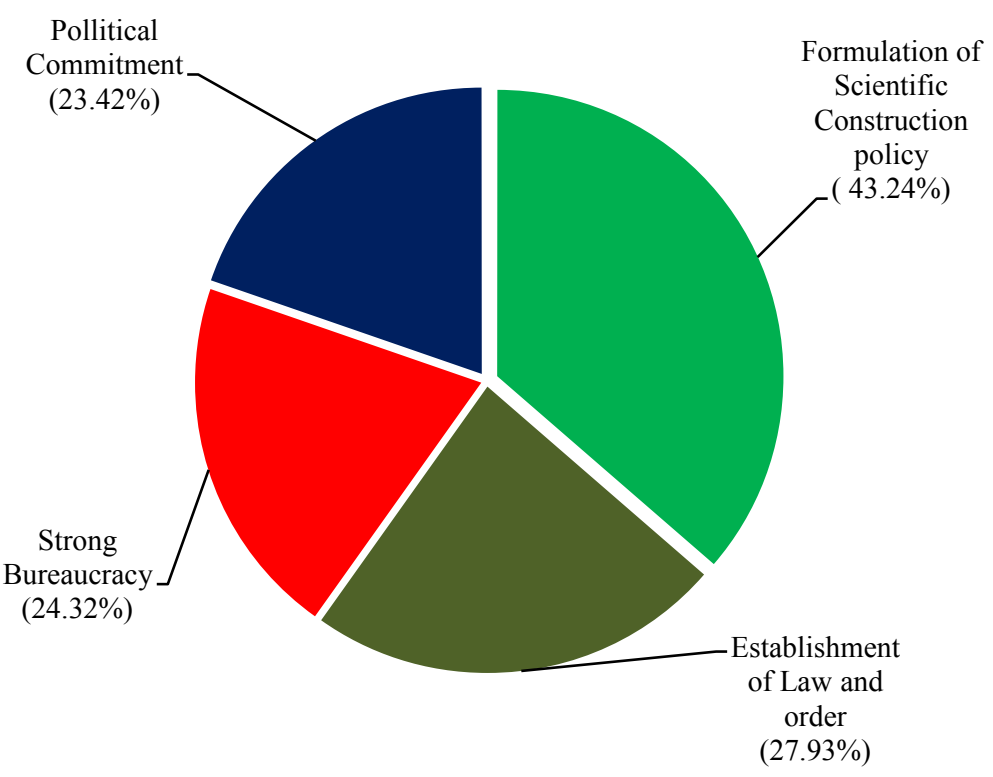

Figure 5: Solutions to overcome poor construction performance.

\section{Leadership qualities}

Now, since the respondents realized the need for leadership in construction with reasons prevalent in many dimensions and levels, the study next examined the individual leadership qualities prevalent among Nepalese construction professionals with multi dimension approach (i) leadership traits (ii) leadership behavior and contingency approach, and (iii) authentic leadership development.

One of the objectives of the research was to find out the relative importance of leadership traits as its value to construction professionals in order to get positive construction business results. Twenty number of leadership skills were listed and respondents were asked to rank them according to its value to them. Relative Important Index (RII) statistic was used to rank the leadership Traits. The result of RII is presented in Figure 6.

According to the results of this study Top 7 Most Important leadership traits as preferred by Nepalese Construction professionals are shown in Table 1.

Similarly, Top 5 least important traits are presented in Table 2.

According to Chartered Institute of Building priority of skills said to be required in Construction Industry because of its unique nature are different from those required in other businesses [15]. However, Top 7 leadership traits valued by construction professionals according to this study are similar to the survey results carried out in other businesses such as in the survey results of 200 CEOs preferable leadership traits is presented in Table 3. 


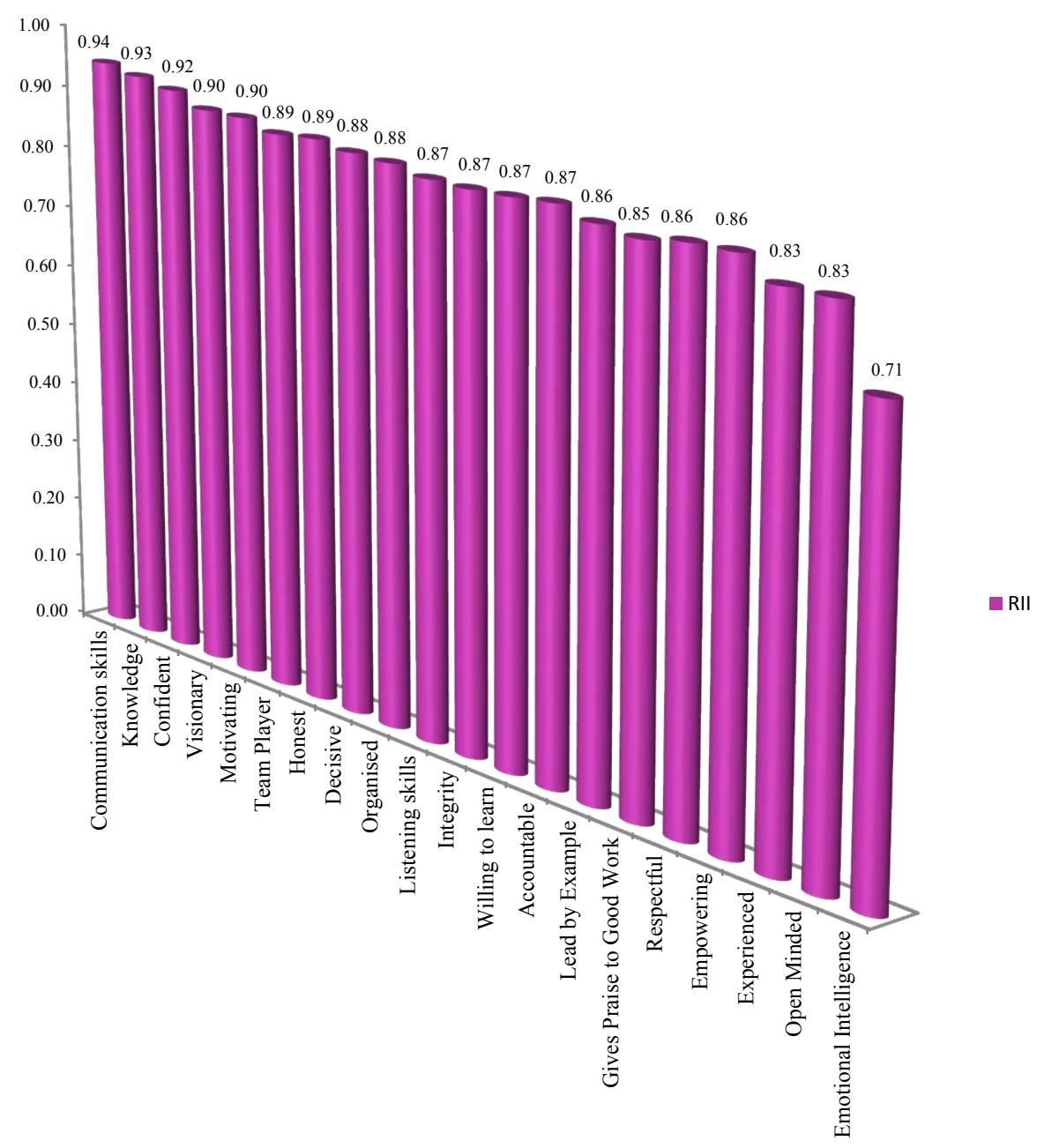

Figure 6: Relative importance of leadership traits as given by RII (Source:...).

\begin{tabular}{|c|c|c|}
\hline Leadership Traits & RII & Rank \\
\hline Communication skills & 0.94 & $1^{\text {st }}$ \\
\hline Knowledge & 0.93 & $2^{\text {nd }}$ \\
\hline Confident & 0.92 & $3^{\text {rd }}$ \\
\hline Visionary & 0.90 & $4^{\text {th }}$ \\
\hline Motivating & 0.90 & $4^{\text {th }}$ \\
\hline Team Player & 0.89 & $6^{\text {th }}$ \\
\hline Honest & 0.89 & $6^{\text {th }}$ \\
\hline Source: CIB, 2009. & & \\
\hline
\end{tabular}

Table 1: Top 7 most important construction leadership traits.

The fact that the communication stood up at the top most position ahead of knowledge, majority of leadership traits that came within top seven are rather soft skills, and the scores given by RII to all the listed 20 skills are in proximity to each other indicates softer skills such as communication skills, honesty, motivation, which are equally important than hard core skills such as experience and knowledge. The results highlight the importance of softer skills even in the construction sector which is said to give emphasis upon technical skills as well as the management of money, Machine and materials called three M's. This once again proves that leading man with effective leadership skills comes in front in every construction management. Another

\begin{tabular}{|c|c|c|}
\hline Leadership Traits & RII & Rank \\
\hline Emotional Intelligence & 0.71 & $20^{\text {th }}$ \\
\hline Experienced & 0.83 & $18^{\text {th }}$ \\
\hline Open Minded & 0.83 & $18^{\text {th }}$ \\
\hline Gives Praise to Good Work & 0.85 & $17^{\text {th }}$ \\
\hline Empowering & 0.86 & $16^{\text {th }}$ \\
\hline Source: CIB, 2009 & & \\
\hline
\end{tabular}

Table 2: Top 5 Least important construction leadership traits.

interesting finding is that communication skills came at the top in the similar studies done by Bhangale and Devalkar and Xiong [16]. Some argue that the traits of leaders in the construction industry are unique Chartered Institute of Building [15]. The department of construction management, University of Washington D. C. shows that construction leaders are similar, have similar skill sets, and face similar leadership obstacles as other business leaders.

\section{Leadership behavior and style}

Part IV of the survey dealt with the ranges of leadership behavior preferred by the respondents while doing their job. Thus, determining (i) their style of leadership, and (ii) orientation of their leadership behavior i.e. towards people or towards task. 
The answers given by the construction professionals to the leadership behavior were the preferred/habitual style of leadership. One would find himself/herself close to while discounting the effects of situational variables [17]. The results obtained for the preferred styles of leadership can be summarized as in Figure 7.

Majority of the respondents $(72.81 \%)$ said they practice team management in their leadership style which indicates maximum no. of practitioners' leadership behavior are oriented towards both high task and high people meaning they unequivocally value task at hand while establishing smooth relationship with people. This high task and high person style of leadership is compatible with the theory of Blake and Mouton Leadership Grid, which suggests team management is the best approach in getting results from committed people who have common stake in the organization purpose. Also quite number of respondents (19.30\%) favored middle of the road management in their leadership style which suggests they acquire to maintain balance between task and relationship in order to obtain adequate organizational performance. And $4.39 \%$ respondents said they practice country club management which means they give priority to people rather than task and believe satisfying relationship promotes friendly atmosphere and work tempo. Meager $(2.63 \%)$ of respondents suggested their behavior are oriented towards high task. Few people represented by authority obedience i.e. they focus on job design where there is minimum people interference. During survey only one respondent suggested his behavior is oriented towards low task and low people i.e. he preferred exerting minimum effort and delegate their jobs to others, which falls into the category of impoverished management.

In this study, maximum number of respondents (92\%) preferred

\begin{tabular}{|c|c|}
\hline Quality & CEOs Rating (as most important), $\%$ \\
\hline Communication Skills & 52 \\
\hline Ability to Motivate People & 47 \\
\hline Honesty & 34 \\
\hline Ability To Listen & 25 \\
\hline Team Building Expertise & 24 \\
\hline Analytical skills & 19 \\
\hline Aggressive in Business & 10 \\
\hline Source: Vancouver, 2000 & \\
\hline
\end{tabular}

Table 3: What CEOs identify as key leadership traits. either high task and high people (Team management with $72.81 \%$ ) or medium task and medium people (Middle of The Road management with 19.30\%). Perfect Team Management has score of (9.9) according to leadership grid developed by Blake and Mouton while in this study the respondents falling into team management grid scored not that perfect of meager 6.5 meaning they are not much high either in task or in people i.e. they preferred medium task and medium people just enough for organizational performance or that is to say they do not put that extra little effort or are not motivated/empowered to go beyond self and look for the shared vision as investigated by contemporary theories of leadership.

\section{Leadership Orientation}

However, in construction, evidence, from leadership researches, suggest that different styles of leadership are needed in different situations [18]. The manager may therefore find that one can lead successfully in some settings but not in others. There are several key variables that may have an influence in determining the suitable leadership style in construction projects such as nature of the project, size of the project, time perspective, organization structure etc. But the present study examined the effect of two variables. They are (i) Type of organization, and (ii) Nature of project on the leadership styles of the professional practitioners.

\section{Type of organization}

Three typical participants of Nepalese construction industry namely client organization, consultant organization, and contractor organization were surveyed in order to see if the organization structure/ type affects the style of leadership of professionals involve in these organizations. The average leadership orientation score (people score and task score) for each type of the organization is presented in Figure 8.

It is found from the results, contractors scored highest in both people and task score (6.60and6.67). Clients scored lower score than the contractors in both task and people $(6.45,6.38)$. In the consultant organizations, score for task is relatively lower than score for people, which means leadership orientation is slightly oriented towards people rather than task.

\section{Nature of work}

Respondents were asked to specify the nature of work they were

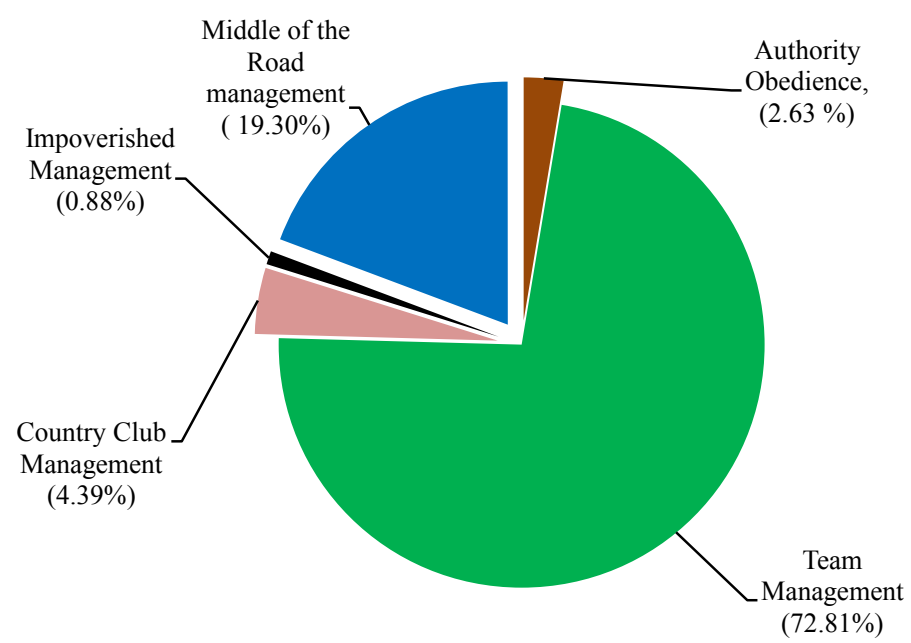

Figure 7: Ranges of leadership style as preferred by the professionals. 
Citation: Dahal KR, Manoj KC (2016) Leadership Management among Construction Professionals in the Context of Nepal. J Entrepren Organiz Manag 5: 187. doi:10.4172/2169-026X.1000187

Page 7 of 9

involved in. They had three options to choose from (i) Design (ii) Design and construction, and (iii) Construction supervision. The data were analyzed to see if there is significant difference between the leadership behaviors exhibited by these three groups of practitioners. The results obtained were as shown in Figure 9.

Results showed practitioners involved predominantly in construction were more oriented towards people rather than task while practitioners involved predominantly in Design as well as Design and Construction scored almost equal both in people as well as Task.

These results indicated that the professionals preferred not significantly varied style of leadership irrespective of the nature of work they are involved in or the type of organization they work for. This result contradicts with studies undertaken on the effect of situational variables existing in construction [19]; which emphasizes on switching approaches to leadership as the situation demands?

Strength positions in key dimensions of authentic leadership development

Another part of field survey titled "Authentic leadership selfassessment questionnaire" dealt with the strength position in key dimensions of authentic leadership development namely (i) self- awareness (ii) internalized moral perspective (iii) balanced processing, and (iv) relational transparency among the respondents. The results obtained are presented in Figure 10.

Overall Average Authentic leadership score obtained from among the responses of 114 respondents in each of the four dimensions was less than 16 which indicated that the respondents were weaker in each aspect of authentic leadership. Two key dimensions i) Self Awareness of (Average score 15.54) and ii) Internalized moral perspective (Average score 15.12) can be considered as Average strength but not stronger which requires the range of $16-20$ while the other two dimensions Balanced processing and Relational Transparency score below 15 with 14.97 and 14.69 respectively which fall into the lower range of 15 and below indicating weaker Authentic leadership.

The research assumed Successful Practitioners are strong in Authentic Leadership. Successful respondents were selected from the sample population. The criterion of selection of successful practitioners was the formal leadership position they occupied in their respective job. Average authentic leadership score of successful practitioners are presented in Figure 11.

The results showed that successful practitioners of Nepalese construction Industry score high in two dimensions i) Self Awareness and ii) Balanced Processing. They also scored near to 16 in Internalized

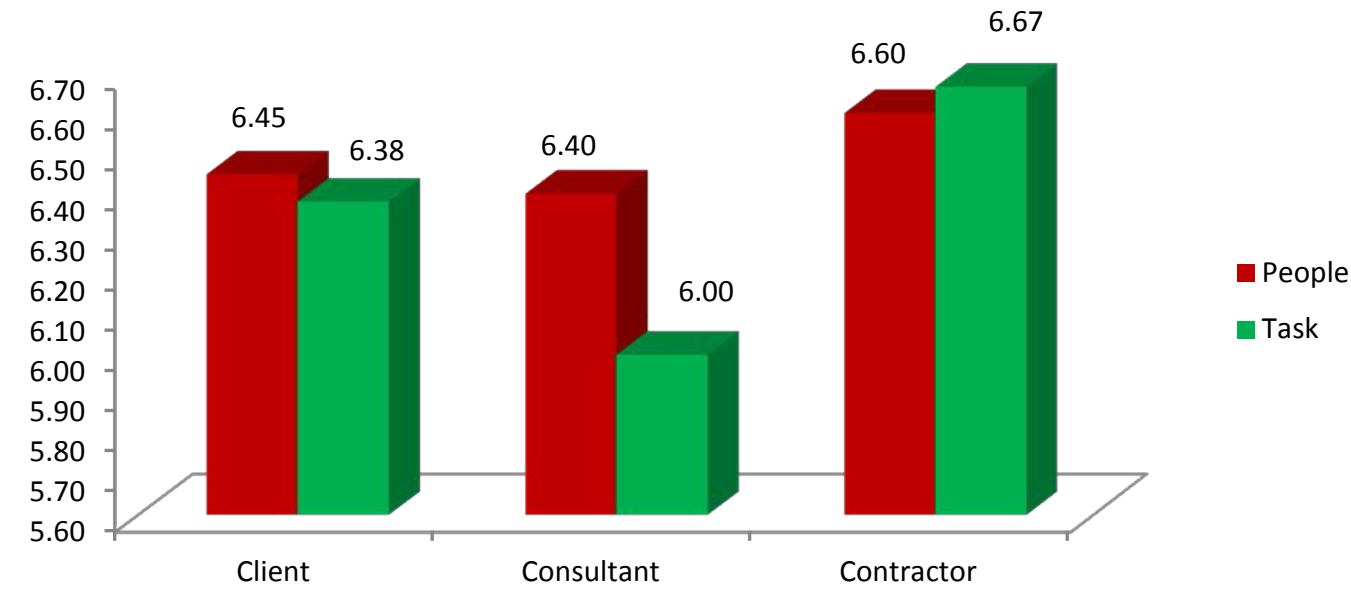

Figure 8: Relationship between leadership orientation and organization type.

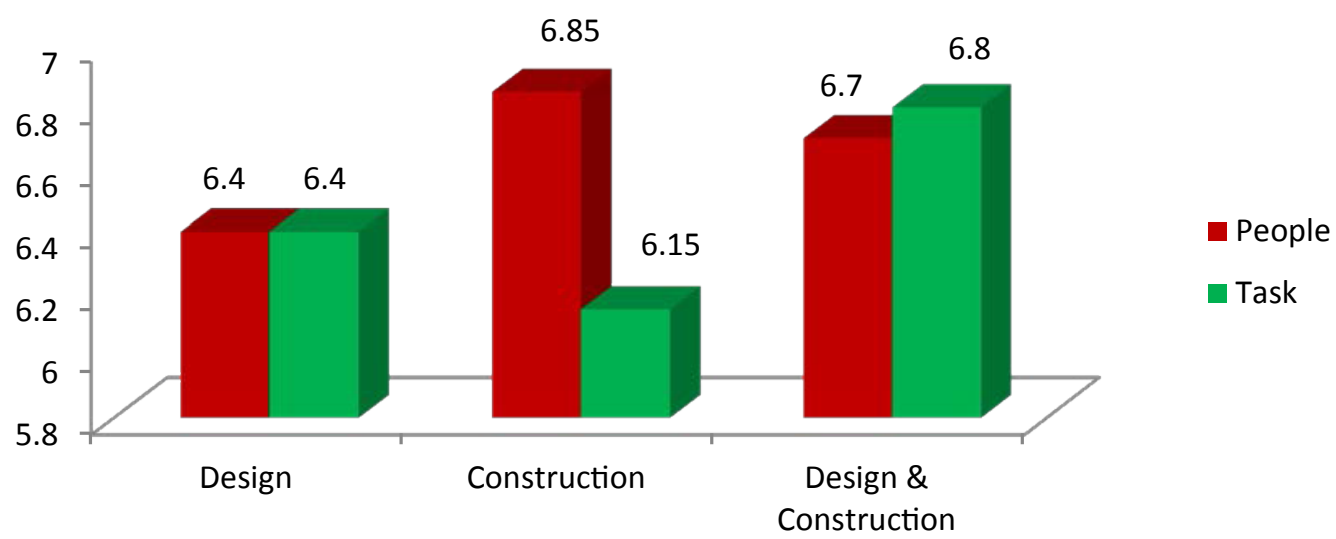

Figure 9: Relationship between leadership orientation and nature of work. 
Citation: Dahal KR, Manoj KC (2016) Leadership Management among Construction Professionals in the Context of Nepal. J Entrepren Organiz Manag 5: 187. doi:10.4172/2169-026X.1000187

Page 8 of 9

Moral perspective. And as in the cases of all the respondents surveyed, score in Relational Transparency is the lowest of all. Also, the authentic leadership scores were compared among the respondents of varying age and experience. The results are shown in Figures 12 and 13.

The results showed that there is no significant difference between the Authentic Leadership strength of various Age Groups. However, results shown in Figure 12 indicate that Authentic
Leadership strength is much lower (less than 15) in the fresh group of engineer (less than 5 yrs. of experience). The results indicated experience does matter in development of Authentic Leadership and the fresh Engineers lacked leadership qualities which owes partly to the impractical engineering education system that gives too much emphasis on technical aspects and totally ignores softer part of engineering such as leadership in undergraduate engineering curriculum.

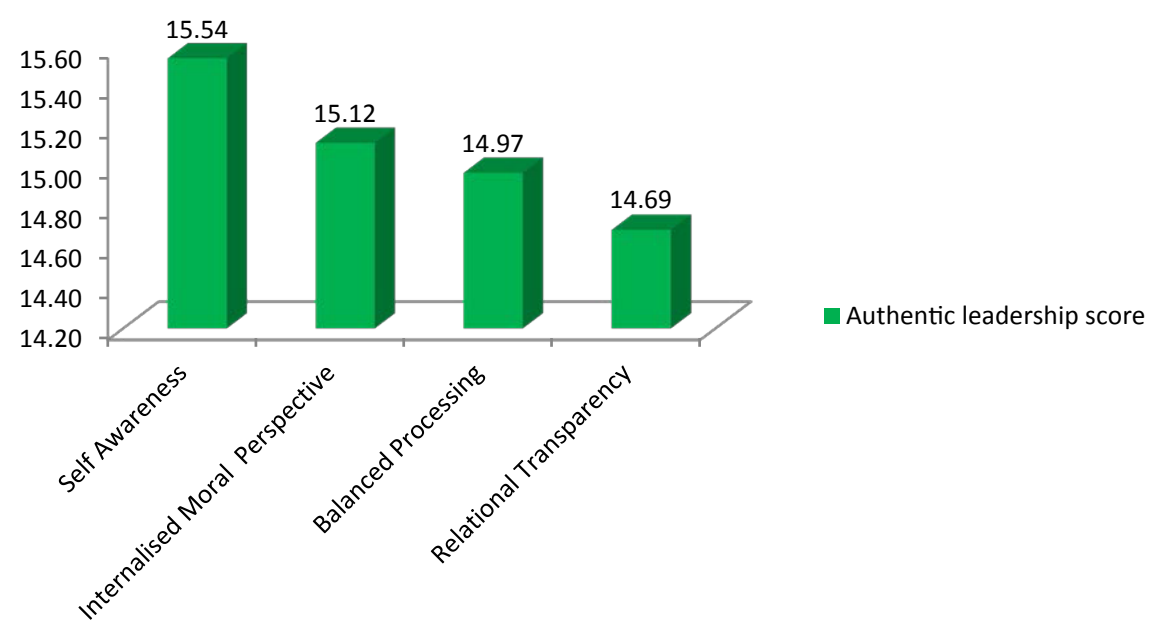

Figure 10: Authentic leadership strength in key dimensions.

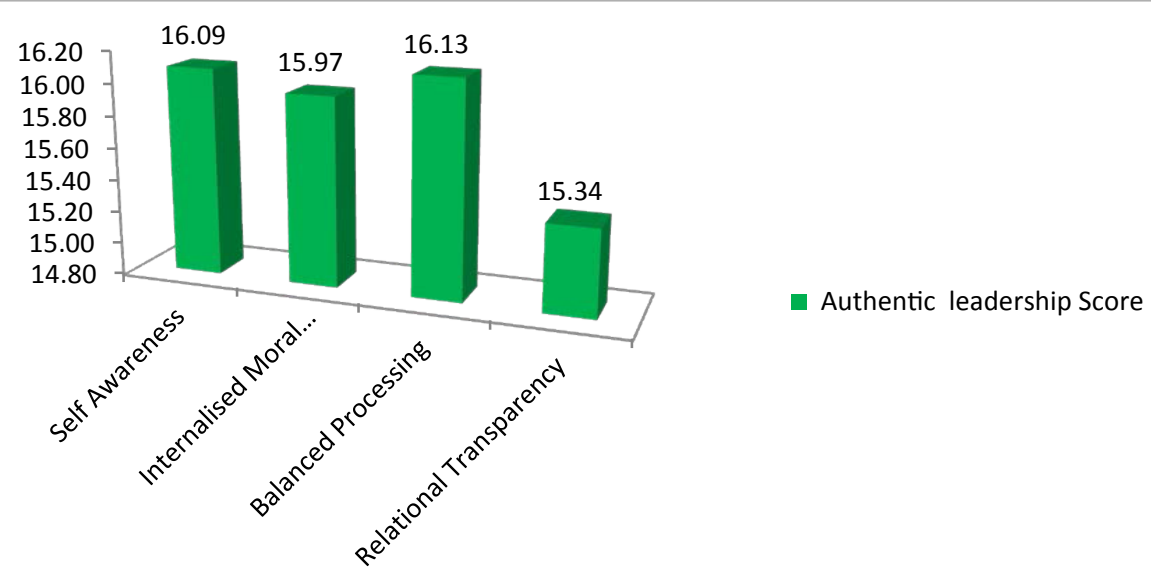

Figure 11: Authentic leadership strength of successful practitioners.

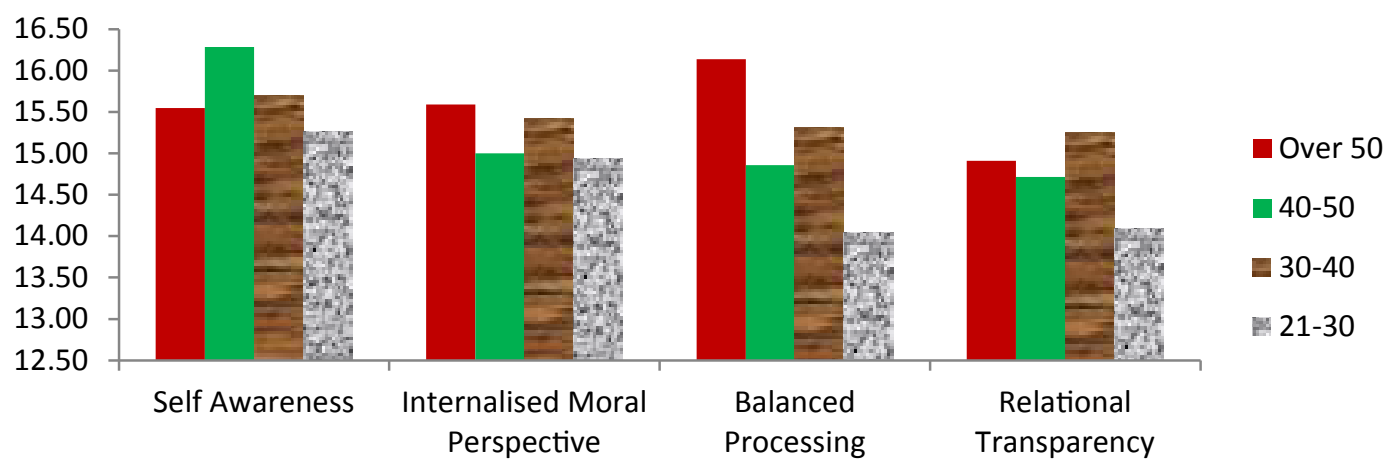

Figure 12: Authentic leadership strength positions among various age groups. 


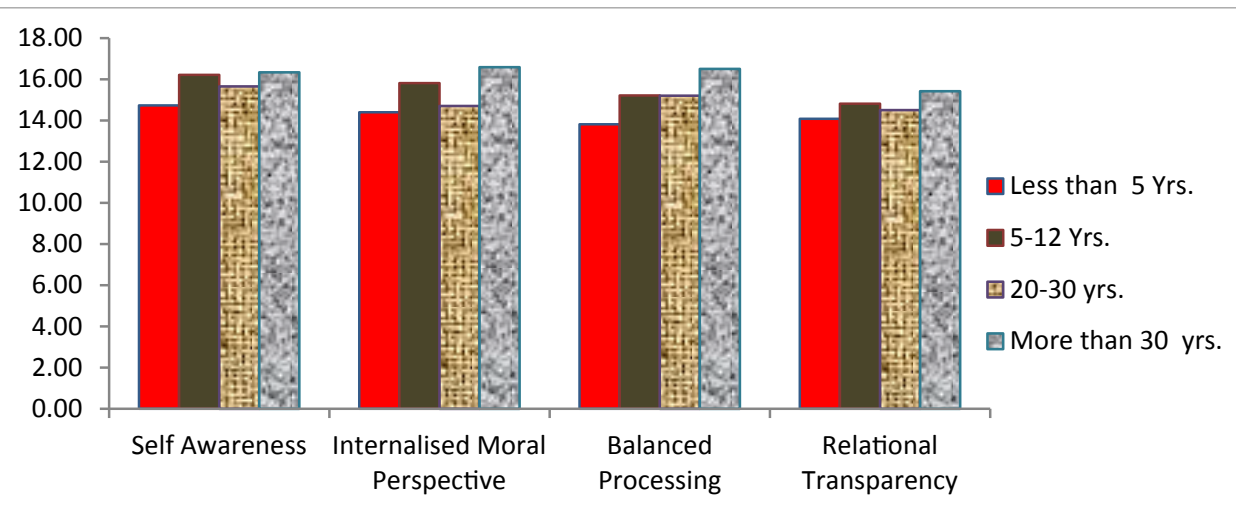

Figure 13: Relationship of authentic leadership strength \& experience of professionals.

\section{Conclusions}

Despite there is recognition of leadership at all levels of the construction industry, emphasis is placed on the technical aspects. Thus, management receives inadequate attention. This is very common case in many Nepalese construction industries. The study has found out the realization of need for leadership in many levels and dimensions of Nepalese construction industries. Furthermore, it has also concluded that there are problems in many levels and dimensions of Nepalese construction industries along with effective leadership. Moreover, authentic leadership, softer leadership traits, such as, communication and honesty, and team management. There are contradictory views regarding similarity of valued leadership traits/skills in construction as compared to other businesses because of the unique nature of construction industry. However, this study found out that Nepalese construction practitioners prioritize similar sets of leadership traits. Nepal has the pressing need for infrastructure development of the nation. Thus, there is a need for new breed of professional leaders. Hence, leadership development should be given equal emphasis on technical and managerial aspects in construction industries along with the professionals in the context of Nepal.

\section{Acknowledgements}

We would like to acknowledge Dr. Khem Raj Sharma, Mr. Anjay Mishra, and Robert Dangol, for their contribution during preparation of this paper.

\section{References}

1. Ofori G, Toor SUR (2012) Leadership and Construction Industry Development in Developing Countries. Journal of Construction in Developing Countries 1: $1-21$.

2. Ofori G, Toor SUR (2012) Leadership Development for Construction SMES Rheden. The Netherlands, Engineering Project Organisations Conference.

3. Fairholm MR (2004) Different perspectives on the practice of leadership. Public administration review 64: 577-590.

4. HilleBrandt P (2000) Economic Theory and the Construction Industry (3rdedn), Basingstoke, Macmillan, London.

5. Panthi K, Farooqui RU, Ahmed MS (2010) An investigation of the leadership styles of Construction Managers in south Florida. Florida International University, Miami, Florida

6. Skipper C, Bell L (2006) Assessment with 360 degree evaluations of leadership behavior in Construction Project Managers. Journal of Management in Engineering 22: 75-80

7. Skipper C, Bell L (2006) Influences impacting leadership development. Journal of management in Engineering 22: 68-74.

8. Vroom VH, Jago AH (2007) The role of situation in leadership. American Psychologist 62: 17-24.
9. Bass B, Avolio B (1997) The Full Range of Leadership development. Bass/ Avolio and Associates, New York.

10. Gomez-Mejia L, Balkin D (2012) Management: People/Performance/Change. Pearson Education Inc, New Jersey.

11. Kotter J (1990) What Leaders really do? Harvard Business Review pp: 103-111. 12. Anon (2012) Constructiong futures.

13. Toor S, Ofori G (2008) Taking leadership research into future: A review of empirical studies and new directions for research. Engineering, Construction and Architectural Management 15: 352-371.

14. Luthans F, Avollio B (2003) Authentic Leadership: A positive Developmental approach. In: Cameron, eds. Positive Organisational scholarship: Foundations of a New Discipline. San Fransisco: CA: Berrett -Kohler, pp: 241-58.

15. Spatz DM (1999) Leadership in the construction industry. Practice Periodical on Structural Design and Construction 4: 64-68.

16. Xiong R (2008) Leadership in Project Management. Georgia.

17. Rowlinson S, Ho K (1993) Leadership style of Construction Managers in Hong Kong. Construction Management and Economics 11: 455-465.

18. Bresnen M (1986) The leader orientation of Construction site Managers Construction Engineering and Management 112: 370-386.

19. Hammuda IM, Dulaimi MF (1997) The Effects of the situational variables on the leadership styles in Construction Projects. Association of Researchers in Construction Management, Cambridge. 